\title{
Equidad y Desarrollo
}

Volume 1 | Number 4

Article 1

January 2005

\section{Editorial}

Luis Fernando Ramírez Hernández

Universidad de La Salle, Bogotá, Iramirez@lasalle.edu.co

Follow this and additional works at: https://ciencia.lasalle.edu.co/eq

\section{Citación recomendada}

Ramírez Hernández, L. F. (2005). Editorial. Equidad y Desarrollo, (4), 5-6. https://doi.org/10.19052/ed.363

This Editorial is brought to you for free and open access by the Revistas científicas at Ciencia Unisalle. It has been accepted for inclusion in Equidad y Desarrollo by an authorized editor of Ciencia Unisalle. For more information, please contact ciencia@lasalle.edu.co. 


\section{Editorial}

La arquitectura del sistema financiero internacional descansa hoy sobre las bases del denominado Acuerdo de Bretton Woods, suscrito hace ya más de seis décadas. En ese entonces, los hombres de Estado tuvieron la determinación de construir un orden económico duradero que facilitara el crecimiento económico de la posguerra.

El mayor problema residía en que no se contaba con una institución multilateral que pudiese detener a los países en su práctica de devaluación competitiva. Fruto del Acuerdo fue el establecer dos organizaciones de carácter multinacional: el Fondo Monetario Internacional (FMI) y el Banco Mundial. La tarea el FMI consistiría en mantener el orden en el sistema monetario internacional y la del Banco Mundial sería promover un desarrollo económico general.

Nadie duda que la experiencia vivida durante la segunda mitad del siglo XX muestra que tanto el FM como el Banco Mundial supieron responder a las fuerzas económicas dinámicas de la época. Sin embargo, en la actualidad, ante un nuevo conjunto de eventos, algunos estiman que ha llegado el momento de que estas instituciones se adapten a las necesidades actuales y no a las circunstancias geopolíticas del siglo pasado.

En particular, se critica el hecho de que estas organizaciones que tanto repercuten en los países en desarrollo muestran un déficit democrático que impide mejorar la representatividad de los países miembros. En el Banco Mundial y en el FMI se aplica un régimen de cuotas, ya que la cuota determina en número de votos de un país en el Directorio Ej ecutivo. $Y$ de acuerdo con esto, casi la mitad del número de votos está en manos de siete países.
El nuevo esquema del FMl y del Banco Mundial debería subrayar la necesidad de una mayor participación de sus principales prestatarios, los países en desarrollo. Una redistribución del número de votos no solo corregiría el desequilibrio actual entre países industriales, emergentes y en desarrollo, sino que también intensificaría el diálogo entre las naciones miembros.

Pero adicionalmente, existen otros elementos que obligan a repensar la forma en que estos organismos se adaptan a los cambios en el mapa económico y los centros de poder en el mundo. Por una parte, la transición demográfica. Las poblaciones de los países industrializados envej ecen mientras que los países en desarrollo mantienen altos índices de población económicamente activa. Este cambio necesariamente originará una mayor cantidad de flujos de capital hacia las naciones con población joven, estimulando su crecimiento económico.

De otra, se encuentra la dinámica de las economías de los países emergentes, cuya participación en el producto y comercio mundial ha aumentado considerablemente y se prevé que se incrementará aún más en la primera mitad del presente siglo, en la medida en que la tecnología les permita fomentar sus índices de productividad.

Así mismo, está el surgimiento de Asia en la economía mundial. Desde el punto de vista del PIB, tres de las cuatro economías nacionales más importantes a nivel internacional - China, India y J apón - son de Asia, y en conj unto poseen alrededor del $40 \%$ de la población mundial.

En síntesis, si bien las instituciones de Bretton Woods respondieron a la dinámica de la economía en la 
última mitad del siglo XX, deben ahora adoptar medidas de reforma estructural tendientes a fomentar los procesos democráticos a nivel mundial, entre ellos algunas formas para aumentar la representación, la transparencia y la rendición de cuentas logrando que la arquitectura del sistema financiero internacional refleje las nuevas fuerzas subyacentes.
Los esfuerzos que se hagan para alcanzar esas metas deben afrontar la realidad del poder mundial, pero encierran la posibilidad de que tanto los países industrializados como los países en desarrollo resulten más beneficiados por una cooperación entre naciones más participativa que permita escuchar las voces de los excluidos y los marginados.

Luis Fernando Ramírez Hernández Director 